Original Contribution

\title{
TREATMENT OF FRACTURES OF THE DISTAL FEMORAL - OVERVIEWS OF OSTEOSYNTHESIS FUNDS
}

\author{
N. Dimitrov* \\ Department of Orthopaedics and Traumatology, University Hospital "Prof. Dr. Stoyan Kirkovich", \\ Stara Zagora, Bulgaria
}

\begin{abstract}
Distal femoral fractures thigh up from 4 to $9 \%$ of all fractures of the femur. There is a direct relationship between the mechanism of receipt of the lesion and the age, sex and the type of fracture. Caused mainly by high-traumatic effects and lead to a high degree of disability. For these reasons, injuries in this anatomical area are of great social importance. The goal of the distal femur fractures treatment is to recover patients preoperative status for the shortest possible period. This may be achieved by open reposition and internal fixation. Recent years are characterized by significant progress in the treatment of this type of fracture. This is due to the rapid development of new and sound biomechanical implants: $95^{\circ}$ Angled blade plates (ABP), condylar buttress plates (CBP), dynamic condylar screw (DCS), retrograde intramedullary nails (two locking or a locking screw + spiral blade), LISS-plates. The discussion in the treatment of these fractures is concentrated in the choice of means of internal fixation by which to achieve the greater stability of the individual type of fracture.
\end{abstract}

Key words: femoral fractures, internal fracture fixation, mini invasive techniques

Distal femoral meta-epiphysis fractures are varied in morphologic and prognostic regard. Caused mainly by high-traumatic effects and lead to a high degree of disability. For these reasons, injuries in this anatomical area are of great social importance. Their treatment is difficult. The high percentage of complications observed during treatment - deformities, contractures, non-union, arthrosis of the knee joint, infections and others. That's why it requires careful consideration and precise approach.

Distal femoral fractures thigh up from 4 to $9 \%$ of all fractures of the femur (1). There is a direct relationship between the mechanism of receipt of the lesion and the age, sex and the type of fracture (1-6). They occur in a bimodal distribution: 50+ years of age, predominantly in females with osteoporosis, who sustain low energy trauma, and 15-50 years of age, predominantly in mails, sustaining high-energy trauma. In older patients these fractures achieve a high percentage: $85 \%$ of victims are persons over 50 years (1) and female with

\footnotetext{
* Correspondence to: Nedko Dimitrov, $M D, P h D$, Department of Orthopedics and Traumatology, Medical Faculty, Trakia University, Stara Zagora, Bulgaria,e-mail:dimitrovnedko@yahoo.com
}

osteoporosis are about $68 \%(7,8)$. These fractures are the result of low-energy injuries received in an indirect mechanism (fall on folded knee, bending, torsion) and are often multifragmentary, and/or intra-articular. Open fractures are rare. In young people (mostly young men) fractures of the distal femur are the result of high energy trauma (accidents, falls from height). The mechanism is usually direct. The resulting fractures are broken, dislocated, intra-articular, sometimes found. Such fractures occur in patients with polytrauma. Only $20 \%$ of patients the fracture of the distal femur is isolated damage.

The goal of the distal femur fractures treatment is to recover patients preoperative status for the shortest possible period. This may be achieved by open reposition and internal fixation. Recent years are characterized by significant progress in the treatment of this type of fracture. This is due to the rapid development of new and sound biomechanical implants: 95 - Angled blade plates (ABP), condylar buttress plates (CBP), dynamic condylar screw (DCS), retrograde intramedullary nails (two locking or a locking screw + spiral blade), LISS-plates.

The discussion in the treatment of these fractures is concentrated in the choice of 
means of internal fixation by which to achieve the greater stability of the individual type of fracture. Achieving stable reposition in any of the used implant stable fixation is determined by the quality of the bone, the type of fracture, reposition achieved, choice and position of the implant.

Disturbance of the biomechanics of the knee joint causes early arthrosis changes, so priority in the surgical treatment of distal femural fractures is the restoration of axial ratio in the
DIMITROV N.

distal femur. Articular surfaces of the distal femur and tibial plateau are non-congruent and supplemented by two menisci. In intra-articular fractures meniscal damage was observed in 8 to $12 \%$ and concomitant fracture of the patella - 15\% of all fractures of the distal femur. The damage to blood vessels is approximately $3 \%$, of nerves $-1 \%$ of all distal femur fractures $(9$, $10)$.

Modern classification of the distal femur fractures is Mullers et al. (11). (Figure 1)

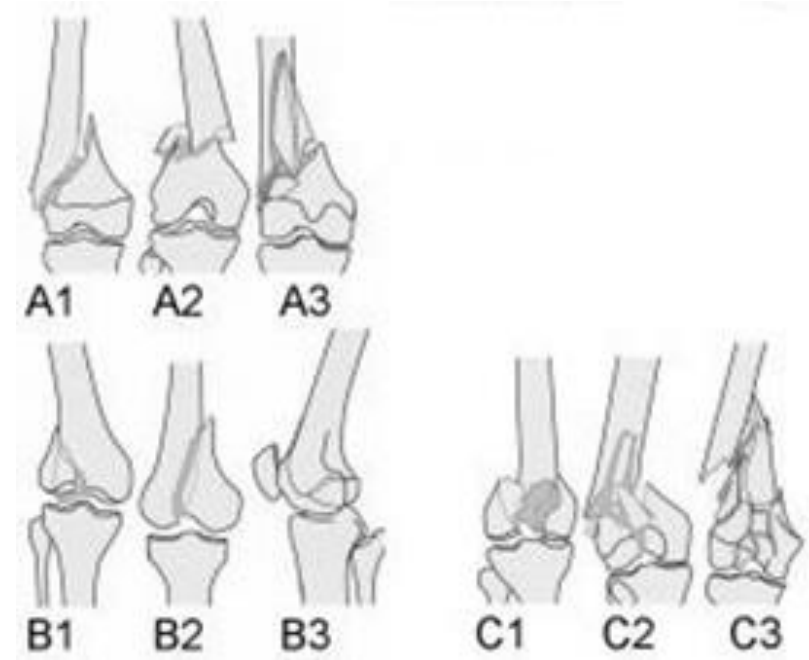

Figure 1. Schematic representation of the classification of Muller et al. (11)

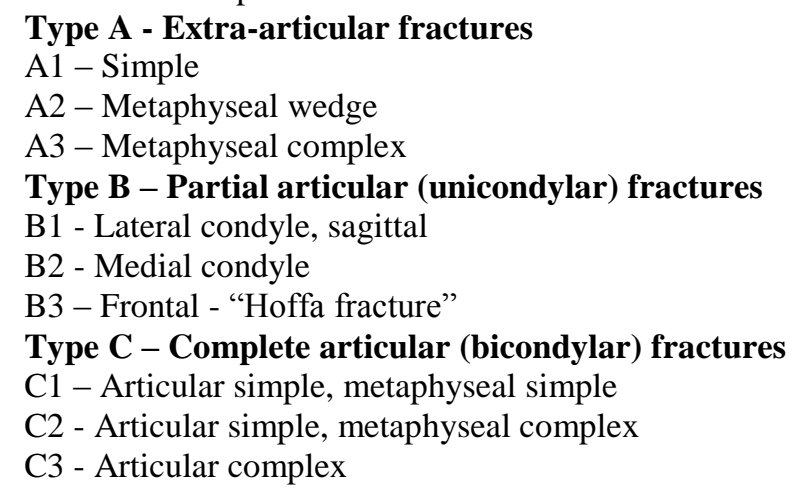

Supracvondylar stabilization of distal femur fractures has always been a huge challenge for traumatologist. As supracondylar area has good rehabilitation potential, in the past, these fractures were treated by skeletal traction and plaster immobilization (12). This treatment, rehabilitating fracture in length, would not control the rotation and reposition and could not keep congruent joint surface.

Open reposition of distal femur fractures in experienced surgical hands allows an exact repositioning of the articular surfaces, stable fixation and early mobilization of joints.

The options for surgical treatment of fractures of the distal femur are as follows:

1. $95^{\circ}$ Angled blade plates (ABP)

2. Dynamic condylar screw (DCS)

3. Condylar buttress plates (CBP)
4. Flexible intramedullary femoral nails: Rush rods, Enders nails, Zickel nails

5. Antegrade intramedullary nails (AFN)

6. Retrograde intramedullary nails (RFN)

7. External fixtion

8. Primary knee replacement Less Invasive Stabilization System (LISSplates).

The distal fixation (Figure 2) of the various implants is:

- Condylar support (buttress) plate subchondral

- $95^{\circ}$ Angled condylar blade plate (ABP)

-1.5 to $2 \mathrm{~cm}$

- DCS $-2 \mathrm{~cm}$

- $\mathrm{RFN}-6 \mathrm{~cm}$

- LISS-plate - subchondral 


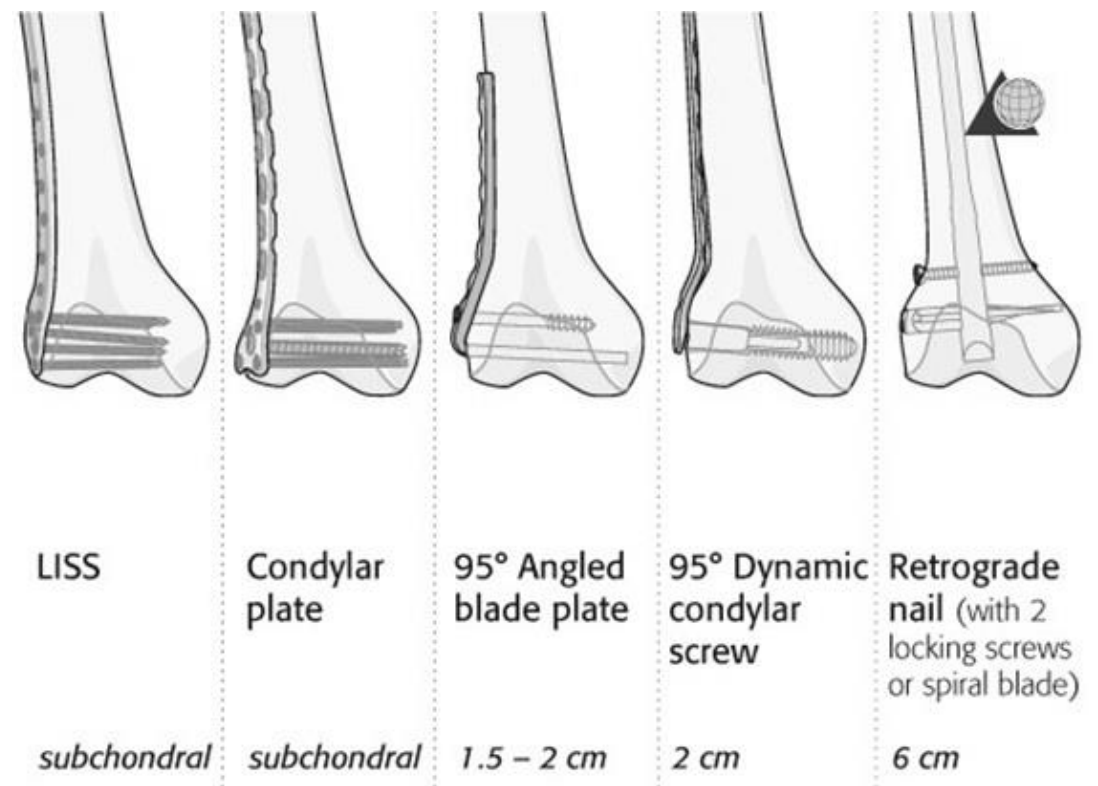

Figure 2. Distal fixation with different implants (AO)

The results of surgical treatment of distal hip fractures improves not until AO group published initial results in 1970 (13), placing at the base of this treatment AO - principles of anatomical joint reconstruction and rigid internal fixation. Subsequent studies confirmed these results. For example Schatzker et al compared the results of these internal fixation with non-operative treatment of 71 distal femur fractures. $45 \%$ of the cases were treated by internal fixation, and were observed better results in $75 \%$ of them, while in the group of non-operative treatment - only $32 \%$ there were good results (14). This trend continued in 1970 and $1980(15-18)$.

Multiple implants were developed to implement these AO-principles, such as retrograde intramedullary nails (RFN), $95^{\circ}$ Angulated condylar blade plates (ABP), dynamic condylar screw (DCS) and condylar buttress plates (CBP) $(19,20,21)$.

Despite advances in technology for implants, their use remains limited in multi-fragment fractures and osteoporosis bones. RFNs, although mini-invasive, are helpless to stabilize multi-fragment intra-articular fractures $(\mathrm{C} 2-\mathrm{C} 3)(22,23)$.

Fixation provided at the distal fragment through central inter-fragmentary screw DCS, was not anticipated due to its large core diameter and a small shred size (21). Using the ABP puts technical difficulties because it requires 3-dimensional visualization of the distal fracture segment. To avoid this, it was developed a simple tool to use - dynamic condylar screw (DCS) - which requires only a two-dimensional visualization (24). However, both implants require removal of a significant amount of bone from the distal fragment and for their placement are not suitable for intraarticular multi-fragmentary fractures. On the other hand, there are not angular fixing stability using the condylar buttress plate and therefore fractures, synthesized with it, tend to varus collapse and/or debricolage of synthesis $(15,25)$.

Another disadvantage of the above osteosynthesis funds to achieve rigid fixation and anatomic reposition is the use of extensive surgical access. This makes inevitable widespread stripping of the soft tissues, and results in disruption of blood flow to the fracture ends $(26,27)$.

Large parts of the proximal and distal fragment are bare and devitalized. As a result, bone defects required filling of the defect with bone graft hoping to improve fracture healing (28).

Mast et al in 1989 first reported the importance of reducing surgical dissection of the fracture site and surrounding soft tissue used for reduction of fractures. They call it "indirect reduction" of the fracture. It aims to maintain blood flow to the fracture edges and reduce the frequency of non-union in operated cases (29, $30)$. Subsequently Krettek and co-workers (24, $26,27,31$ ) build on this concept, emphasizing the need to achieve more relative than absolute stability of the fracture by internal fixation. They also offer minimum interference on the fracture area, which can be accomplished by submuscular plate "dragging" on the side of the femur (minimally invasive percutaneous plate osteosynthesis - MIPPO) $(24,32)$

Early experience with internal fixation of the distal supracondylar hip fractures is 
characterized with increased functionality compared to non-surgical treatments. Inherent in all surgical techniques have complications, such as: poor union, pseudoarthrosis, infection, need for bone grafting and others. Miclau et al., 1998 in case studies with such fractures, which needs bone grafting and were treated with rigid fixation, establish the frequency range from 0 to $87 \%$ (31). The high percentage of bone grafting is associated with the need to use operational techniques, sparing surrounding soft tissues. According Bolhofner
DIMITROV N.

et al, 1996 investigated 57 cases of distal femur fractures found time for bone union average of 10.7 weeks. In two of the cases it was observed delayed bone union, more than 16 weeks. There were no pseudoarthrosis (29)

On Tables 1 and 2 are presented (in literature) results of surgical treatment of distal femur fractures using various osteosynthesis funds and their advantages and disadvantages. Table 3 shows the rigidity of the implants compared to $95^{\circ}$ Angled condylar blade plate (ABP).

Table 1. Results from the surgical treatment of fractures of the distal femur using various means osteosynthesis

\begin{tabular}{|c|c|c|c|c|c|}
\hline Implant & $\begin{array}{l}\text { Approximate } \\
\text { number of } \\
\text { reported cases }\end{array}$ & $\begin{array}{l}\text { Good or } \\
\text { excellent } \\
\text { results }(\%)\end{array}$ & $\begin{array}{l}\text { Non-union } \\
(\%)\end{array}$ & $\begin{array}{l}\text { Malunion } \\
(\%)\end{array}$ & $\begin{array}{l}\text { Infection } \\
(\%)\end{array}$ \\
\hline Angled blade plate & 500 & $52-85$ & $0-7$ & $5-19$ & $5-8$ \\
\hline Dynamic condylar screw & 120 & $71-74$ & $0-10$ & $0-5$ & $0-5$ \\
\hline Flexible nails & 200 & $72-84$ & $0-2$ & NR & NR \\
\hline Intramedullary nails & 150 & $76-100$ & $0-18$ & NR & NR \\
\hline Supracondylar nails & 500 & 69-91 & $0-10$ & $0-17$ & $0-5$ \\
\hline LISS $^{\mathrm{TM}}$ plate & 570 & $72-88$ & $0-10$ & $0-6$ & $0-6$ \\
\hline External fixation & 60 & $64-88$ & $0-8$ & $0-15$ & $0-12$ \\
\hline
\end{tabular}

Table 2. Advantages and disadvantages of osteosynthesis funds for distal femur fractures

\begin{tabular}{|c|c|c|}
\hline Implant & Advantages & Disadvantages \\
\hline Angled blade plate & Strong implant & $\begin{array}{l}\text { Technically demanding, } \\
\text { may split condyles }\end{array}$ \\
\hline Dynamic condylar screw & $\begin{array}{l}\text { Easier insertion, compression of } \\
\text { simple intercondylar fractures }\end{array}$ & $\begin{array}{l}\text { Large volume of bone } \\
\text { removed for screw }\end{array}$ \\
\hline Condylar buttress plate & $\begin{array}{l}\text { Easy insertion, multiple screw } \\
\text { holes, easy to contour, useful } \\
\text { features for multifragmentary } \\
\text { fractures }\end{array}$ & $\begin{array}{l}\text { Weaker, medial plate required } \\
\text { for stability in multifragmentary } \\
\text { fractures }\end{array}$ \\
\hline Flexible nails & $\begin{array}{l}\text { Easy insertion, minimal soft tissue } \\
\text { disruption }\end{array}$ & $\begin{array}{l}\text { Poor hold or intra-articular } \\
\text { fractures, additional support always } \\
\text { required }\end{array}$ \\
\hline $\begin{array}{l}\text { Antegrade intramedullary } \\
\text { nails }\end{array}$ & $\begin{array}{l}\text { Minimal soft tissue disruption, } \\
\text { reamings act as autograft }\end{array}$ & Poor hold in distal fragment \\
\hline Supracondylar nails & $\begin{array}{l}\text { Minimal soft tissue disruption, } \\
\text { reamings act as autograft }\end{array}$ & $\begin{array}{l}\text { Loss of reduction, anterior } \\
\text { knee pain, potential patella- } \\
\text { femoral damage }\end{array}$ \\
\hline LISS $^{\mathrm{TM}}$ plate $^{1}$ & $\begin{array}{l}\text { Minimally invasive approach, } \\
\text { screw lock into plate, } \\
\text { multiple screw holes }\end{array}$ & Technically demanding \\
\hline External fixation & Minimal soft tissue disruption & $\begin{array}{l}\text { High incidence of pin track and } \\
\text { deep infection, may have to span } \\
\text { knee joint causing stiffness, poor } \\
\text { control of joint fragments }\end{array}$ \\
\hline Total knee replacement & $\begin{array}{l}\text { Useful in elderly with pre-existing } \\
\text { arthritis, low fractures }\end{array}$ & Few cases reported \\
\hline
\end{tabular}

Table 3. Rigidity of implants compared to $95^{\circ}$ Angled condylar blade plate (ABP).

\begin{tabular}{|l|l|}
\hline $95^{\circ}$ Condylar Plate & $100 \%$ \\
\hline LISS-DF & $75 \%$ \\
\hline Dynamic Condylar Screw & $56 \%$ \\
\hline
\end{tabular}


Osteosynthesis using LISS-system (Less

Invasive Stabilization System - LISS)

The idea of biologically attached plate osteosynthesis of supracondylnar distal femur fractures by LISS-treatment system was patented in 1990 (Figure 3) and took more than two years to gather support and to initiate
DIMITROV N.

product development. At the beginning of the project have emerged problems, the main problem was the possibility of "blind" placement of the plate. Soon after, they appeared even greater challenges, namely the attachment of the retainer to the bone and determining optimal anatomical shape.

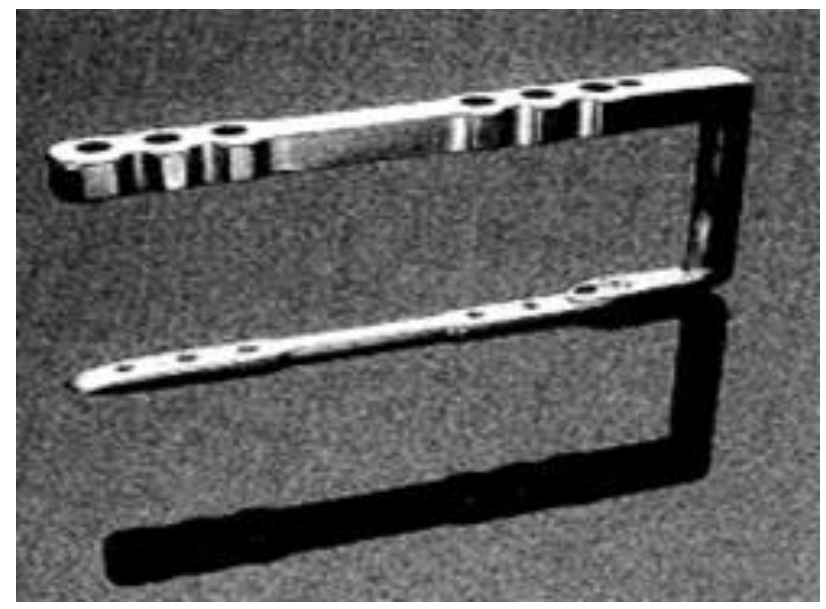

Figure 3. The first prototype of LISS-system

The first implantation of LISS was made in 1995. The studies lasted four years multicentre clinical trial for mechanical and biomechanical efficiency of LISS. Following approval of the Technical Commission of the AO (AO-TK) and is seen worldwide as a new surgical method. LISS-project is a challenge for all participants and is a good example of the importance of interdisciplinary collaboration in the development within of surgical project.

LISS-system finds applications in submuscular plate implantation technique popularized by Krettek et al. (33). This technique can easily be performed using and DCS, does not require extensive surgical dissection at the lateral aspect of the femur. The plate DCS can squeeze proximally in submusle case and then to fix the central condilar screw. Screws in the diaphyseal-metaphyseal fracture component may also be placed by percutaneous way.
Experimental studies by injection of contrast dye penetrant show that there is a cavity beneath $\mathrm{m}$. vastus lateralis, which allows passage of the plate and keeping the perforator vessels of the femur $(26,27)$.

\section{LISS-characteristics}

- Multiple angular-locking screws in the distal end of the plate (7 pieces);

- Insertion handle, allowing submuscular movement proximal to femur;

- Percutaneous placement of selftapping monocortikal screws in diaphyseal part of the hip;

- Locking screws to the plate.

LISS-distal hip has left and right thigh implants lengths 5, 9 and 13 holes in the proximal part of the plate (Figure 4).

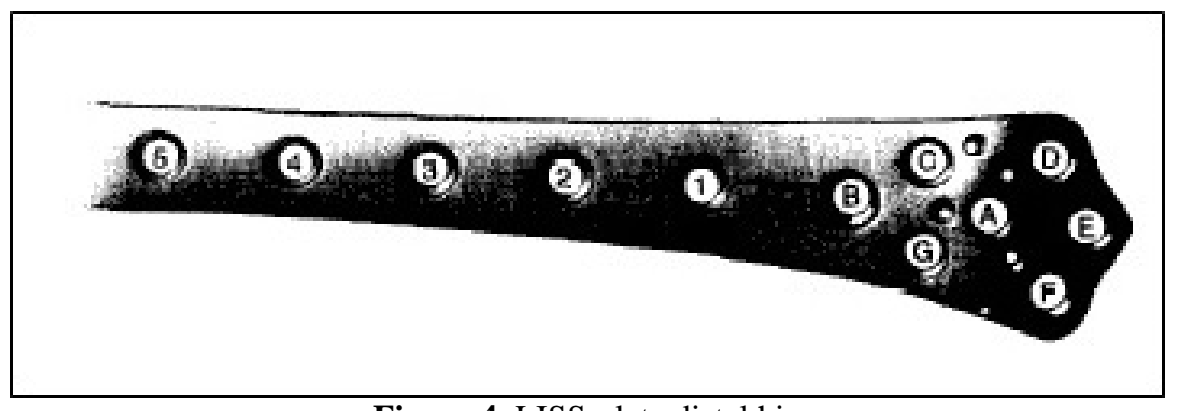

Figure 4. LISS-plate distal hip

The screws for fixing to the bone in the distal part of the plate are of lengths $85,75,65,55$ and $40 \mathrm{~mm}$. Screws with a length of $26-28 \mathrm{~mm}$ used for proximal cortical fixation. All screws are locked in the plate. For distal attachment using 7 screws. LISS-system is designed to be fully stable, in comparison with conventional plate systems. These characteristics make this 
osteosintesis system very convenient for treatment of osteoporotic cases. LISS-system construction shows greater axial strength, compared to RFN, for both normal and osteoporotic bone. This is explained by better distribution of axle load in LISS-system. A larger number of screws in LISS-system leads to an even distribution of load and therefore to a smaller local deformation.

LISS-system is a new surgical concept. It is used for classical open reduction of the fragments through direct visualization of intraarticular components, combined with closed manipulation of the metaphyseal-diaphyseal fracture components using supporting tools. We can consider LISS-system as "internal fixator" rather than plate.

LISS-system is designed as an internal fixator where the screws are locked in the plate (Figure 5). The forces are transferred from the bone on the screws and then - on the plate. The plate no lies close to the bone. Locking screw on the plate provides stability of synthesis and no risk of losing reposition $(34,35)$. It is also not impaired blood flow into the lock, because there is no close contact between bone and plate - fixator. The optimal distance between the plate and the bone is $2 \mathrm{~mm}$.

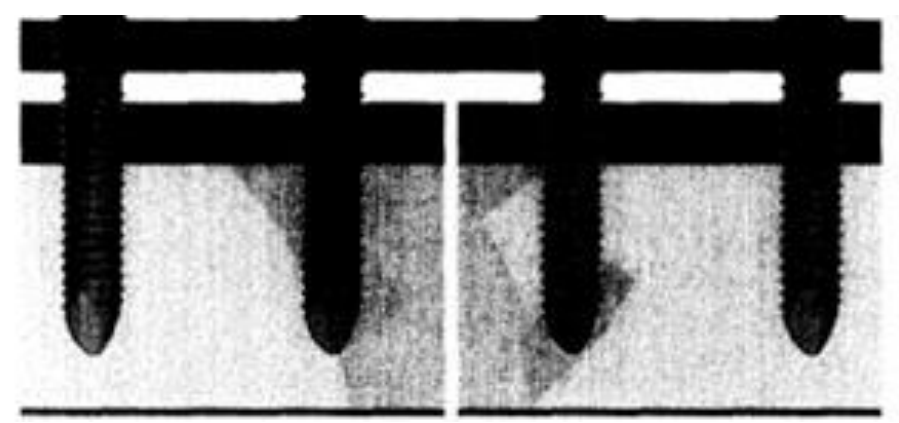

Figure 5. LISS-system as an "internal fixator" where the screws are locked in the plate

Mechanical stability provided by the LISSsystem technique of bridging fixation is appropriate for early rehabilitation and the result is a secondary bone adhesion with callus formation at the fracture site.

LISS-system fixation is based on the principle of bridging fixation, because there are best results when used on broken metaphysical fracture type A2, A3, C2, C3. If applied in bifragmented simple fractures without compression between fragments, non-union rate is very high. Therefore standard compression plates: angulated blade plate (ABP) and dynamic compressive plate (DCP LC), are used with priority for open reposition of such bifragmented simple metaphysical fractures, creating a compression on the fracture site.

$\mathrm{n}$ general, bridging technique plates must be longer than the plates, used for open conventional technique, in order to provide relative stability.

Similarities with external fixator:

LISS-system screws have a larger core diameter to to withstand at a largest bending moment and the larger cutting forces. This, together with the screw head, locked to the plate, allows uni cortical attachment to diaphysis. The advantages of this are:
- it is not necessary to measure the length of each screw separately, i.e. all diaphyseal screws can be equally long;

- metaphyseal screws may be lengths of larger steps.

LISS-system screws, like Schanz-pin are selfdrilling, self-tapping, which simplifies the instrumentation and surgical technique. As such, screws push bone when placed with drill. Thus, the fixing is maintained, but is not receives reposition the fragments. Using the conventional plate techniques, fixation and reposition with incorrectly contouring plate will lead to failure of fracture reposition. Back - proper contouring plate will help fracture reduction as cortical screws will approach the plate to the bone.

Just the opposite is LISS-system: acting as an "internal fixsatorr" fracture reposition must be achieved before fixed with LISS-plate. LISSsystem combines the advantages of condylar plates (easy placement), DCS and ABP (fixed angle between plate and screws) and external fixator (plate stands, "hang" over the bone) and disrupt minimally periosteal blood supply of the fragments. LISS-plates are anatomic contouring for left and right limb, so it is not require additional contouring. The tapered upper edge of the plate allows easy placement in submuscular case under $\mathrm{m}$. vastus lateralis through small skin incisions. 
LISS differs from conventional angular stabilizing plates on three points (36):

1. LISS distal locking screws are more convenient for installation and more efficient than the ABP. Submuscular placement of $\mathrm{ABP}$ is impossible without extensive surgical access. shallow thread of the fastening screws and the thicker core allow for less trauma to the cancellous bone and a greater resistance to bending. The angular stability technique when placing of the implant, introduced and encouraged by the father of AO M. Muller, was crucial in the development of LISS for treating metaphyseal and epiphyseal fractures of the distal hip. LISS technique is an advantage over other techniques when it comes to multifragmental fractures of the distal femur.

2. Biological aspects of LISS - RS-FIX demonstrate superiority among the plates due to the minimal contact (point) of the surface of the bone. Thus plates with PCFIX allowing minimal disruption of the blood supply and good recovery (preserving) in bone biology. At the bottom of LISS-plate gets smaller gap between the plate and the bone in its placement. Thus LISS acts as a "contactless" plate If technology is properly applied. This is achieved by locking screws, which fix the plate to the bone without creating friction between the plate and the bone surface. Elevation of the plate is such that it is near the cortical fracture fragments.

3. The proximal locking screws are selfdrilling, self-tapping with the possibility of monocortical fixation, which facilitates operating equipment and is a prerequisite for minimally invasive placement through the skin.

\section{Evaluation of reposition and stabilization}

After completion of fragments fixation are possible intraoperative full passive movements without effort. Radiographs in the anteroposterior and lateral protection and assessment of fracture reposition answer the following questions:

1. What is the valgus / varus position?

2. Is there a significant hyperextension of the distal femoral condyle?

3. Is there deviation in the sagittal plane?

4. What is the position of the LISS-plate to distal femur?

5. Are all the screws locked in the plate?

6. Is there penetration of some distal screws in femuropatelar or femurotibial joint?

7. Are all monocortical screws properly placed in the middle of the femoral diaphysis (Figure. 6)?

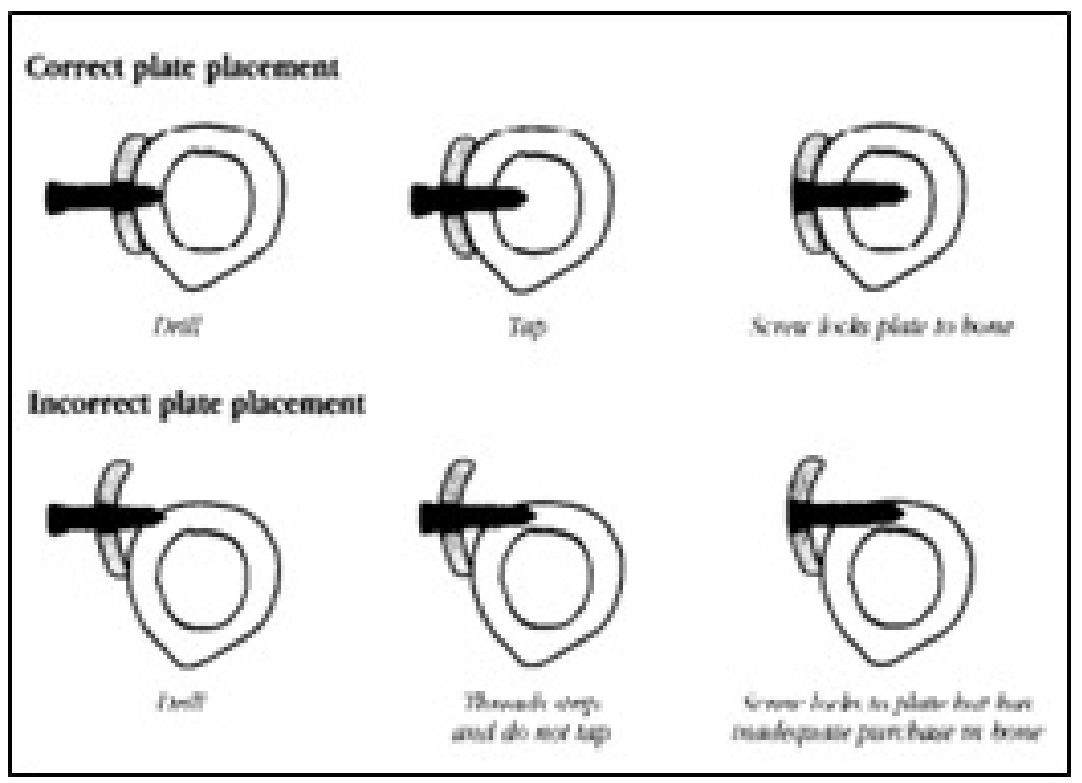

Figure 6. Correct placement and variations of the most frequent incorrect position of the locking screws in the proximal aspect of the plate - slightly forward or rearward relative to the middle part of the proximal femur.

LISS-system has been developed to supplement MIPPO - techniques $(37,38)$ and follows the principles of biological osteosynthesis. It consists of anatomic contouring plate for left and right limb with the possibility of disposing of seven locking screws in the distal femoral condyle to providing angular stability of fixation. The presence of external rentgenonegative handle allows retrograde submuscular placing a plate and the opportunity for percutaneous fixation with monocortical self-drilling and self-tapping screws. Using unicortical (as opposed to bicortical) screws is a potential cause of loosening of screws in proximal femoral diaphysis, particularly in osteoporotic bone 
(39, 40, 41) [Kanabar P, 2007; Wong M-K, 2005; Fulkerson E, 2007]. Before placing the screws distal femoral fragment is repositioned and articular surface is reconstructed. Using the principles of external fixator (not in vain LISS-system is likened to a internal "fixator"), preservation of fracture biology eliminates the need for bone grafting in most cases [Ostrum R.F., Geel C., 1995]. The knee joint motion volume shows a significant difference depending on used surgical fragments reposition technique - open or MIPPO technique. The exact anatomical fracture reposition and early mobilization of joints are key aspects to achieving good range of motion in the knee joint.

The traditional bone grafting has been the hope of replacing the non-vital bone fragments, resulting from in open techniques for the treatment of fractures. This often is required when using mini-invasive techniques, where it is stored biology of fracture. The traditional bone grafting has been the hope of replacing the non-vital bone fragments, resulting from in open techniques for fractures treatment. This often is required when using mini-invasive techniques, where it is stored biology of fracture. Kregor et al, 2001 reported series with equal distribution of distal femur fractures by type A and B treated with LISS-operative system and has reported a $100 \%$ degree of coalescence. Only 5\% of cases have had primary bone grafting.

Depending on the type of reposition - MIPPO or open technique, the terms are different: MIPPO - techniques contribute to faster bone consolidation - an average time of 3 (2-5) months than the open reposition technique - an average time of $4(3.5$ - 5) months . It is considered that it is preserved bone biology, fragments are not deperiostated and bone circulation is saved. Similar results have been reported in the literature with $100 \%$ consolidation in acute postoperative fracture for 3.5 months on average $(36,43,44)$.

The incidence of periprosthetic fractures in the future will increase, given the aging population and the increased number of primary knee arthroplasty in connection with osteoarthritis of the knee (45). The treatment of periprosthetic fractures is more complex task, considering osteoporosis in the elderly, an increased risk of periprosthetic infection, difficulty in reposition of fragments around the femoral component of the knee prosthesis, and the presence of metalosis (46).
The extent of infectious complications in our series is low, despite the presence of open fractures (Gustilo I -II degree). This is due to the standard pre-operative antibiotic prophylaxis, early debridement in place of open and minimally fracture technique for placement of LISS-plate. (28). Deep infections require secondary surgical treatment - lavage, drainage, antibiotic therapy.

LISS-system is convenient and easy to work and specific technical difficulties, except the above, are not met. The results achieved are in accordance with the recommendations given by the manufacturer of LISS-system, namely: LISS plates should be fixed to the proximal fragment with at least 5 monocortical screws and fixing its distal fragment should be performed at least four locking screws. In intra-articular fractures and those with Hoffa fragment, interfragmentary placement of screws should be in such a position that does not interfere with locking screws placed in LISS-plate. It it very important the lateral inclination of $10^{\circ}$ to the lateral side of the distal femur. Otherwise receive pain over ileotibial band, which is the reason for the earlier removal of the implants.

11 fractures of the distal femur $\mathrm{A}-\mathrm{C} / \mathrm{AO}$, incl. all severity of these fractures can be successfully stabilized by LISS.

Based on the above we can draw the following conclusions about the advantages and disadvantages of LISS-system:

Advantages of LISS:

1. Short terms of bone consolidation;

2. Without using autogenous bone graft in $95 \%$ of cases;

3. Stable distal femur support $-100 \%$ even in osteoporotic bone;

4. Angular stability;

5. Axial stability;

6. Without contouring of the plate;

7. Low infections due to closed (sub muscular) equipment;

8. Minimal damage to the blood supply and bone;

9. Minimum damage to the soft tissues;

10. Priority in osteoporotic and periprosthetic fractures.

Disadvantages of the technique

1. Difficulty in using closed reposition techniques.

2. Shandelmaier et al suggests that improper positioning of LISS-plate to the femoral diaphysis may lead to an incorrect placement of the proximal screws, which causes unstable fixation of the plate to the bone. This incorrect 
position of the LISS - plate in the sagittal plane is reason for postoperative pain (43). Loosening of the proximal screws as a result of incorrect placement is with a greater incidence in the longer plates (40).

Changes in surgical technique with the emergence of specially designed implants, ensuring the high stability of fixation, allowing to achieve significantly improved treatment outcomes for victims with serious fractures above. However, the degree of complications remains high. As a reason for this is the primary burden of traumatic injury, the increase in the number of fractures in the elderly against the expressed osteoporosis. The rational choice of treatment method, taking into account the severity of the resulting injury, general condition of the patient, presence of concomitant damage and pathology from the internal organs, provides achieving the maximum possible score in each case. The further development and improvement of minimally invasive method of treating these injuries and structures for their implementation is the most promising direction.

LISS-system as LCP is good for fixation of fractures of the distal femur, especially for complex intra-articular fractures. The operative time is reduced. Reduced blood loss performed operations without transfusion. Provides good angular stability. The greatest effect in adult patients with osteoporosis. Minimally invasive techniques, as LISS-system are designed for fixation of the fracture and minimize trauma to soft tissues and retain biology of fracture. Disposal of LISS-plate, even in open techniques provides less trauma to the soft tissues and less postoperative stiffness of the knee joint. Minimum are infectious complications. No further bone grafting. LISSsystem is an optimal tool for all fractures of the distal femur, especially multi-fragmentary intra-articular fractures and those with osteoporosis. Achieved early mobility due to the primary stability of the structure.

This technique requires careful planning and experience on the part of the surgical team. Good knowledge of operational techniques and careful preoperative preparation makes LISSsystem safe procedure for the treatment of almost all types of fractures of the distal thigh, incl. periprosthetic fractures. The purpose of this technique is to restore the anatomy of the distal femur to provide stable fixation and help early fracture healing. LISS-the system summarizes the idea of combining biological advantages of MIPPO with the mechanical advantages of the devices for multiple angle fixation.

In LISS-system issue is no longer whether the fracture will heal or whether it will heal properly, and the question is: whether they will fix it correctly.

\section{REFERENCES}

1. Kolmert L., Wulff K. Epidemiology and treatment of distal femoral fractures in adults. Acta Orthop Scand. 53:957, 1982.

2. Helfet D.L. Fractures of the distal femur. In Browner B.D., Jupiter J.B., Levine A.M., Trafton P.G. (eds) Skeletal trauma. Vol 2 Philadelphia JB Lippincott Co, 1643, 1992.

3. Hohl M., Larson R.L. Fractures of the distal femur. In Rockwood C.A., Green D.P. (eds). Fractures. $1^{\text {st }}$ et Vol 2, Philadelphia JB Lippincott Co, 1643, 1975.

4. Schatzker J., Lambert D.C. Supracondylar fracture of the femur. Clin Orhop. 138:77, 1979.

5. Seligson D., Kristiansen T.K. Use of Wagner apparatus in complicated fractures of the distal femur. J Trauma. 18:795, 1978.

6. Wiss D.A. Supracondylar and intercondilar fractures of the femur. In Rockwood CA, Green D.P., Bucholz R.W. (eds). Fractures. $3^{\text {rd }}$ et Vol 2, Philadelphia JB Lippincott Co, 1778, 1991.

7. Arneson T.J. et al. Epidemiology of diaphyseal and distal femoral fractures in Rochester, Minessota 1965 - 1984. Clin Orthop. 188:234, 1988.

8. Martinet O., Cordey J., Harder J. The epidemiology of fracture of the distal femur. Injury. Vol 31, p 62-63, 2000.

9. Stover M. Distal femur fractures: Current treatment, results and problems. Injury. Vol 32, p 3-13, 2001.

10. Neer C.S., Grantham S.A., Shelton M.L. Supracondylar fracture of the adult femur. JBJS. Vol 49(A), p 591-613, 1967.

11. Muller M.E. et al, 1990. The comprehensive classification of fractures of long bones. In Muller M.E., Allgower M., Schneider R., Willenneger H. (eds). Mannual of internal fixation. $3^{\text {rd }}$ ed Berlin Springer-Verlag p 118, 1990

12. Tees J.D. Fracture of the lower end of the femur. Am. J. Surg.. 38, pp. 656-659, 1937.

13. Wenzl H.P., Casey P.A., Hebert, Belin J. Die operative Behanlung der distalen Femufraktur. AO Bulletin, 1970. 
14. Schatzker J., Home G., Waddell J. The Toronto experience with the supracondylar fracture of the femur, 1966-72 Injury. 6, pp. 113-128, 1974.

15. Giles J.B., DeLee J.C., Heckman J.D., Keever J.E. Supracondylar-intercondylar fractures of the femur treated with a supracondylar plate and lag screw. $J$. Bone Joint Surg. 64A, pp. 864-870, 1982.

16. Olerud S. Operative treatment of supracondylar-condylar fractures of the femur. Technique and results in fifteen cases. J. Bone Joint Surg, 54A, pp. 10151032, 1972.

17. Schatzker J. Fractures of the distal femur revisited. Clin. Orthop. 347, pp. 43-56, 1998.

18. Siliski J.M., Mahring M., Hofer H.P. Supracondylar-intercondylar fractures of the femur. Treatment by internal fixation. J. Bone Joint Surg. Am. 71A, pp. 95-104, 1989.

19. Henry S.L. Supracondylar femur fractures treated percutaneously. Clin. Orthop. 375, pp. 51-59, 2000.

20. Henry S.L., Trager S., Green S., Seligson D. Management of supracondylar fractures of the femur with the GSH intramedullary nail: preliminary report. Contemp. Orthop. 22, pp. 631-640, 1991.

21. Iannacone W.M., Bennett F.S., Delong W.G. et al. Initial experience with the treatment of supracondylar femoral fractures using the supracondylar intramedullary nail: a preliminary report. J Orthop Trauma., 8:322-7, 1994.

22. Firoozbakhsh K., Behzadi K., DeCoster T.A., Moneim M.S., Naraghi F.F.. Mechanics of retrograde nail versus plate fixation for supracondylar femur fractures. J. Orthop. Trauma. 9, pp. 152157, 1995.

23. Helfet D.L., Lorich D.G. Retrograde intramedullary nailing of supracondylar femoral fractures. Clin. Orthop., 350, pp. 80-84, 1998.

24. Krettek C., Schandelmaier P., Miclau T. et al. Trnsarticular joint reconstruction and indirect plate osteosynthesis for complex distal supracondylar femoral fractures. Injury. 1:A31-41, 1997.

25. Sanders R., Swiontkowski M., Rosen H., Helfet D. Double plating of communited, unstable fractures of the distal part of the femur. J Bone Joint Surg. 73A, pp 341346, 1991.

26. Farouk 0., Krettek C., Miclau T., Schandelmaier P., Guy I.', Tscherne H. Minimally invasive plate osteosynthesis and vascularity: preliminary results of a cadaver injection study. Injury. 28(Suppl 1):A7-12, 1997.

27. Farouk 0., Krettek C., Miclau T., Schandelmaier P., Guy P. Tscherne H. Minimally invasive plate osteosynthesis: does percutaneous plating disrupt femoral blood supply less than the traditional technique? J Orthop Trauma. 13(6):4016, 1999.

28. Gustilo R.B., Anderson J.T. Prevention of infection in the treatment of one thousand and twenty-five open fractures of long bones; retrospective and prospective analysis. J Bone Joint Surg. 58A, pp 453458, 1976.

29. Bolhofner B.R., Carmen B., Clifford P. The results of open reduction and internal fixation of distal femur fractures using a biologic (indirect) reduction technique. $J$. Orthop. Trauma. 10(6) pp. 372-377, 1996

30. Mast J., Jakob R., Ganz R. Planning and reduction techniques in fracture surgery. New York: Springer-Verlag; 1989.

31. Miclau T., Holmes W., Martin E. et al. Plate osteosynthesis of the distal femur: Surgical techniques and results. $J$ Southern Orthop Assoc. 7:161-170, 1998.

32. Krettek C., Schandelmaier P., Miclau T., Tscherne H. Minimallyinvasive percutaneous plate osteosynthesis (MIPPO) using the CS in proximal and distal femoral fractures. Injury . 1:A2030, 2001.

33. Krettek ., Schandelmaier P., Tscherne H. Distal femoral fractures. Transarticular reconstruction, percutaneous plate osteosynthesis and retrograde nailing]. Unfallchirurg. 99(1):2-10, 1996.

34. Koval K.J., Hoehl J.J., Kummer F.J., Simon J.A. Distal femoral fixation: A biomechanical comparison of the standard condylar buttress plate, a locked buttress plate and the 95 degree blade p1ate.J. Orthop. Trauma.11(7):521-4, 1997

35. Tepic S., Perren S.M. The biomechanics of the PC-Fix internal fixator. Injury. 26(S2):5-10, 1995.

36. Kregor P.J., Stannard J., Zlowodzki M. et al. Distal femoral fracture fixation utilizing the less invasive stabilization system (LISS): the technique and early results. Injury. 32(3):SC32-47, 2001.

37. Miclau T., Martin R.E. The evolution of modern plate osteosynthesis. Injury. 28(suppl), pp A3-A6, 1997.

38. Schandelmaier P., Krettek C., Miclau T. Stabilization of distal femur fractures using the LISS. Tech Ortop. 14, pp 230246, 1999. 
39. Kanabar P., Kumar V., Owen P.J., Rushton N. Less invasive stabilisation system plating for distal femur fractures. $J$ Orthop Surg. 15:299-302, 2007.

40. Wong M-K., Leung F., Chow S.P. Treatment of distal femfral fractures in the elderly using a less invasive plating technique. Int Orthop. 29:117-20, 2005.

41. Fulkerson E., Tejwani N., Stuchin S., Egol K. Menagement of periprostethic femur fractures with a first generation locking plate. Injury. 38:965-72, 2007.

42. Ostrum R.F., Geel C. Indirect reduction and internal fixation of supracondylar femur fractures without bone graft. $J$ Ortop, Trauma. 9, pp 278-284, 1995.

43. Shandelmaier P., Partenhemer A., Koanemann B. et al. Distal femfral
DIMITROV N. fractures and LISS - stabilization. Injur. 32SC55-63, 2001.

44. Schutz M., Muller M., Krettek C., Hontzsch D., Regazzoni P., Ganz R. Minimally invasive fracture stabilization of distal femoral fractures with the LISS: a prospective multicenter study. Results of a clinical study with special emphasis on difficult cases. Injury. 32 (Suppl. 3), pp. SC48-SC54, 2001.

45. Kobbe P., Klemm R., Reilmann H., Hockertz T.J. Less invasive stabilization system (LISS) for the treatment of periprostethic femur fractures - a 3-year follow up. Injury. 39:472-9, 2008.

46. Moran M.C., Brick G.W., Sledge C.B. et al. Supracondylar femur fractures following total knee artroplasty. Clin Orthop. 324:196-209, 1996. 